JURNAL TEKNIK SIPIL

Universitas Muhammadiyah Aceh

Volume 7 Nomor 1 (Juni 2018)

\title{
PENGARUH JENIS SEMEN TERHADAP PERKEMBANGAN KUAT TEKAN BETON DENGAN MENGGUNAKAN BAHAN TAMBAHAN SIKAMENT NN 1,5\% (Suatu Penelitian untuk FAS 0,50 dan 0,55)
}

\author{
Munawir $^{1}$, Khalid $^{2}$ \\ ${ }^{1)}$ Dosen Tetap. Prodi Teknik Sipil, Universitas Muhammadiyah Aceh \\ ${ }^{2)}$ Mahasiswa Prodi Teknik Sipil, Universitas Muhammadiyah Aceh \\ Email :munawir@unmuha.ac.id
}

\begin{abstract}
ABSTRAK
Beton merupakan salah satu bahan konstruksi bangunan. Campuran beton terdiri dari semen, air, agregat dan bahan tambah bila diperlukan. Material semen dalam beton sangat penting dikarenakan semen berfungsi sebagai bahan pengikat antara agregat kasar dan agregat halus. Penelitian ini bertujuan untuk mengetahui pengaruh penggunaan semen Portland Cement Composit (PCC) dan semen Tipe I diproduksi oleh semen Andalas terhadap kuat tekan beton berdasarkan umur beton pada campuran beton dengan nilai Faktor Air Semen (FAS) 0,50 dan 0,55. Perencanaan campuran beton menggunakan metode American Concrete Institute 211.1-91. Ukuran maksimum agregat adalah 31,5 $\mathrm{mm}$. Benda uji yang digunakan pada penelitian adalah silinder beton berdiameter $15 \mathrm{~cm}$ dan tinggi 30 $\mathrm{cm}$. Pada penelitian ini umur pengujian kuat tekan adalah 3, 7, 14, 21 dan 28 hari dengan FAS 0,50 dan 0,55 . Jumlah sampel untuk semua FAS pada setiap pengujian kuat tekan beton adalah 30 buah benda uji untuk masing-masing tipe semen. Berdasarkan hasil pengujian kuat tekan rata-rata beton FAS 0,50 yang menggunakan semen tipe I untuk umur 3, 7, 14, 21 dan 28 hari berturut-turut adalah sebesar $193,34 \mathrm{~kg} / \mathrm{cm}^{2}, 203,72 \mathrm{~kg} / \mathrm{cm}^{2}, 229,18 \mathrm{~kg} / \mathrm{cm}^{2}, 248,99 \mathrm{~kg} / \mathrm{cm}^{2}$ dan $272,57 \mathrm{~kg} / \mathrm{cm}^{2}$. Sedangkan Untuk semen PCC pada umur yang sama kuat tekannya adalah sebesar $139,58 \mathrm{~kg} / \mathrm{cm}^{2}, 169,77 \mathrm{~kg} / \mathrm{cm}^{2}$, $202,78 \mathrm{~kg} / \mathrm{cm}^{2}, 220,69 \mathrm{~kg} / \mathrm{cm}^{2}$ dan $249,93 \mathrm{~kg} / \mathrm{cm}^{2}$. Untuk FAS 0,55 yang menggunakan semen tipe I untuk umur 3, 7, 14, 21 dan 28 hari berturut-turut adalah sebesar $182,97 \mathrm{~kg} / \mathrm{cm}^{2}, 202,78 \mathrm{~kg} / \mathrm{cm}^{2}$, $218,81 \mathrm{~kg} / \mathrm{cm}^{2}, 235,79 \mathrm{~kg} / \mathrm{cm}^{2}$ dan $267,85 \mathrm{~kg} / \mathrm{cm}^{2}$. Sedangkan Untuk semen PCC pada umur yang sama kuat tekannya adalah sebesar $149,02 \mathrm{~kg} / \mathrm{cm}^{2}, 169,77 \mathrm{~kg} / \mathrm{cm}^{2}, 177,31 \mathrm{~kg} / \mathrm{cm}^{2}, 209,38 \mathrm{~kg} / \mathrm{cm}^{2}$ dan $243,33 \mathrm{~kg} / \mathrm{cm}^{2}$. Ditinjau dari jenis semen yang digunakan terlihat bahwa beton dengan menggunakan semen adalas tipe I perkembangan kuat tekan betonnya lebih tinggi dibandingkan dengan PCC baik pada FAS 0,50 dan 0,55 pada umur yang sama.
\end{abstract}

Kata kunci: FAS, kuat tekan beton, semen tipe I, semen PCC dan Sikament NN.

\section{PENDAHULUAN}

Pada proses pembuatan adukan atau campuran beton sangat diperlukan perhatian pengendalian mutu beton. Faktor Air Semen (FAS) merupakan salah satu faktor penting yang sangat mempengaruhi nilai kuat tekan beton. Semakin tinggi nilai faktor air semen maka kuat tekan beton semakin rendah, jika faktor air semen semakin rendah maka kuat tekan beton yang dihasilkan semakin tinggi. FAS yang digunakan untuk penelitian ini 0,50 dan 0,55 dengan tinggi slump yang direncanakan 7,5-10 cm.

Berdasarkan informasi yang tercantumkan pada brosur PT.SIKA, bahan tambah Sikament NN berfungsi untuk mempermudah pekerjaan atau workability berupa mengurangi air campuran dengan tetap menghasilkan beton yang baik bermutu. Bahan tambah ini berbentuk cairan warna coklat tua dan dapat mengurangi air dalam campuran beton hingga 5 $-20 \%$.

Dalam penelitian ini semen yang digunakan adalah semen tipe I dan Portland 
JURNAL TEKNIK SIPIL

Universitas Muhammadiyah Aceh

Volume 7 Nomor 1 (Juni 2018)

Cement Composite (PCC) untuk mengetahui perkembangan kuat tekan beton yang menggunakan bahan tambah Sikament NN. Untuk FAS yang digunakan dalam Penelitian ini adalah 0,50 dan 0,55 , benda uji yang digunakan adalah berbentuk silinder dengan tinggi 30 $\mathrm{cm}$ dan berdiameter $15 \mathrm{~cm}$ sebanyak 60 buah. Untuk pengujian kuat tekan beton pada umur $3,7,14,21$ dan 28 hari. Untuk setiap benda uji yang akan dilakukan pengujian kuat tekan beton pada setiap umur beton adalah sebanyak 3 benda uji. Sebelum pekerjaan pengocoran dimulai, masing-masing material ditimbang beratnya sesuai dengan perbandingan campuran yang diperoleh dari rancangan campuran beton (mix design).

Peneliti berkeinginan untuk mengetahui sejauh mana pengaruh semen tipe I dan PCC merek andalas dengan mengunakan bahan tambahan Sikament NN 1,5\% dari berat semen terhadap campuran beton untuk FAS 0,50 dan 0,55. Dengan adanya penelitian ini dapat diketahui besarnya nilai perkembangan kuat tekan beton pada masing-masing tipe semen sesuai umur beton dan nilai FAS yang digunakan.

\section{TINJAUAN KEPUSTAKAAN}

\subsection{Beton}

Menurut Hanafiah (1995) beton adalah suatu campuran yang bahan dasarnya terdiri dari agregat, semen dan air. Menurut Dipohusodo (1994) beton didapat dari pencampuran bahan-bahan agregat halus dan kasar yaitu pasir, batu, batu pecah, dan bahan tambahan, dengan menambahkan secukupnya bahan perekat semen dan air, sebagai bahan pembantu guna keperluan reaksi kimia selama proses pengerasan dan perawatan beton berlangsung. Agregat halus dan kasar, disebut sebagai bahan susun kasar campuran pada komponen utama beton.

\subsection{Faktor air semen (FAS)}

Faktor air semen (FAS) adalah perbandingan antara berat air dan berat semen.

$$
\mathrm{FAS}=\frac{\text { Berat air }}{\text { Berat semen }}
$$

Menurut Sagel (1993) Faktor air semen yang rendah (kadar air sedikit) menyebabkan air dibagian-bagian semen sedikit, sehingga jarak antara butiran-butiran semen pendek. Akibatnya massa semen menunjukkan lebih berkaitan, karenanya kekuatan awal lebih berpengaruh dan akhirnya batuan semen mencapai kepadatan tinggi.

Menurut Amri (2005) pemilihan faktor air semen harus dibatasi hingga besaran tertentu yang masih dapat menjamin tercapainya kualitas beton yang diharapkan. Suatu hal yang perlu dipikirkan adalah kondisi yang sangat mempengaruhi penentuan perbandingan air semen maksimum yaitu kondisi lingkungan dimana pekerjaan pembetonan akan dilakukan.

Mulyono (2005) menyatakan, air diperlukan pada pembuatan beton untuk memicu proses kimiawi semen, membasahi agregat, dan memberikan kemudahan dalam pekerjaan beton. Air yang berlebihan akan menyebabkan banyaknya gelembung (yang mengandung udara) setelah proses hidrasi selesai. Air yang terlalu sedikit menyebabkan proses hidrasi 
JURNAL TEKNIK SIPIL

Universitas Muhammadiyah Aceh

Volume 7 Nomor 1 (Juni 2018)

tidak tercapai seluruhnya sehingga akan mempengaruhi kekuatan beton, oleh karena itu, perbandingan air dengan semen (faktor air semen) menjadi penting.

Semakin tinggi nilai faktor air semen, semakin rendah mutu kekuatan beton. Namun demikian, nilai faktor air semen yang rendah tidak selalu berarti bahwa kekuatan beton semakin tinggi. Secara umum, nilai minimum yang diberikan sekitar 0,4 dan nilai maksimum 0,65 .

Air yang dimaksud di sini adalah air yang digunakan untuk campuran, dan perawatan beton menurut (Standar Nasional Indonesia) SNI 03-2847-2002 pasal 5 ayat 1, dimana air digunakan untuk campuran beton, harus bersih dari bahan -bahan merusak yang mengandung oli, asam alkali, garam, bahan organik, dan bahan lainnya yang merugikan beton.

Menurut Murdock dan Brook (1999) disimpulkan bahwa untuk semua tujuan, beton yang mempunyai faktor air semen minimal dan cukup untuk memberikan workabilitas tertentu yang dibutuhkan untuk pemadatan yang sempurna tanpa pekerjaan pemadatan yang berlebihan, merupakan beton yang terbaik.

\subsection{Bahan Tambahan Sikament-NN}

Menurut Mulyono (2004), bahan campuran (admixture) dimaksudkan untuk mengubah perilaku beton saat pelaksanaan pekerjaan, jadi dapat dikatakan bahwa bahan campuran lebih banyak digunakan untuk memperbaiki kinerja pelaksanaan, sehingga bahan tambahan lebih banyak digunakan untuk memperbaiki kinerja kekuatannya.

Menurut Subakti (1995) sikament $N N$ merupakan bahan tambahan kimia yang digunakan untuk mempertinggi workability (sifat kemudahan pengerjaan) dan mengurangi jumlah air pencampur (water reducing admixture) dengan bahan dasar berupa gugus sulphonat yang mengandung ion negatif. Penambahan bahan tambahan dalam campuran beton dapat mengurangi penggunaan air 5-20\% tanpa mengurangi workabilitynya.

\subsection{Perencanaan campuran beton (mix design)}

Anonim (2005) perencanaan campuran beton (mix design) antara lain dapat dilakukan berdasarkan metode American Concrete Institute (ACI) 211.1-91. Penentuan jumlah air yang dibutuhkan $1 \mathrm{~m}^{3}$ beton didasarkan pada slump rencana dan diameter agregat maksimum. Secara umum untuk mendapatkan proporsi agregat halus dapat dihitung dengan persamaan fineness modulus yang diusulkan Dobokugakkai yang dikutip oleh Hanafiah (1995) seperti yang diperlihatkan pada Persamaan 2.3. fineness modulus campuran agregat halus (pasir halus + pasir kasar) berdasarkan Anonim (1991) yang dikutip oleh Hanafiah (1995) dalam batasan 2,4 sampai dengan 3,0.

$$
F M_{(f s)} x+F M_{(c s)}(1-x)=F M_{(f a)}
$$

\subsection{Pemeriksaan adukan beton}

Pemeriksaan adukan beton bertujuan untuk mengontrol kembali slump campuran apakah telah sesuai dengan yang direncanakan. Pemeriksaan yang dilakukan terhadap adukan beton segar antara lain pemeriksaan slump (ASTM C.143-90), berat volume dan 
JURNAL TEKNIK SIPIL

Universitas Muhammadiyah Aceh

Volume 7 Nomor 1 (Juni 2018)

kandungan udara (ASTM C.173-94), diperlukan juga pengukuran suhu mortar adukan beton (adukan beton segar) dan suhu kamar pada saat pengecoran untuk perbandingan dengan suhu mortar.

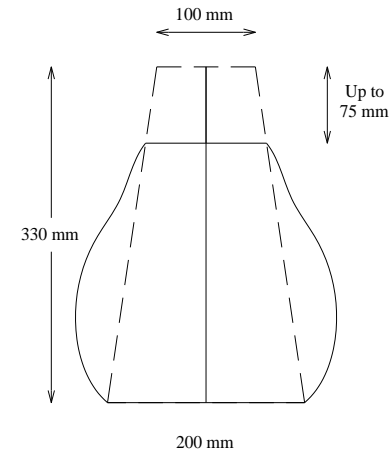

a)

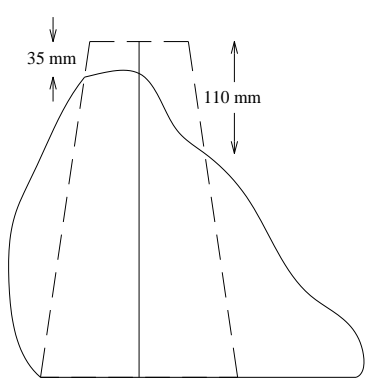

b)

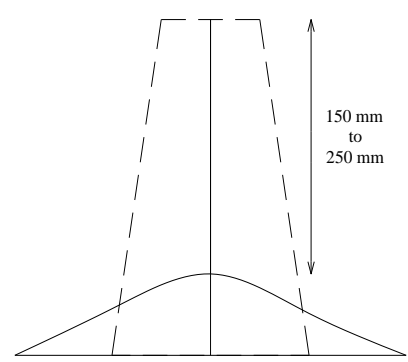

c)

Gambar 2.1 Jenis-jenis Slump: (a) Tipe Ideal, (b) Tipe Geser, (c) Tipe Keruntuhan Sumber : Amri (2005)

\section{METODOLOGI PENELITIAN}

\subsection{Bahan material}

Material yang digunakan pada penelitian ini adalah :

1. Semen tipe I dan PCC ;

2. Air;

3. Agregat halus;

4. Agregat kasar; dan

5. Bahan tambahan ( Sikaments NN 1,5\% )

Semen yang digunakan pada penelitian ini adalah semen tipe I dan semen PCC. Semen tipe I dan semen PCC ini tidak dilakukan lagi pemeriksaan sifat fisis karena telah memenuhi Standar Nasional Indonesia (SNI) 03-2847-2002, namun pemeriksaan hanya dilakukan secara visual terhadap kantong yang tidak robek dan keadaan butiran yaitu tidak terdapat bongkahan-bongkahan yang keras pada semen tersebut.

Air yang digunakan telah tersedia di Laboratorium Konstruksi dan Bahan Bangunan Fakultas Teknik Universitas Muhammadiyah Aceh yang telah memenuhi syarat sebagai air pencampur beton. Agregat halus yang digunakan terdiri atas pasir halus dan pasir kasar. Agregat kasar yang digunakan yaitu kerikil yang lolos saringan diameter 31,5 mm. Semua agregat yang dipakai berasal dari sungai Krueng Aceh. 
JURNAL TEKNIK SIPIL

Universitas Muhammadiyah Aceh

Volume 7 Nomor 1 (Juni 2018)

\subsection{Rencana Benda Uji}

Pembuatan benda uji berbentuk silinder dengan ukuran diameter $15 \mathrm{~cm}$ tinggi $30 \mathrm{~cm}$, Benda uji yang direncanakan dalam penenlitian ini sebanyak 60 buah benda uji dengan pengelompokan sesuai tipe semen dan umur pengujian sebagai berikut:

Tabel 3.1 Pengelompokan Benda Uji Sesuai Rencana Penelitian

\begin{tabular}{|c|c|c|c|c|c|c|c|}
\hline \multirow{2}{*}{ FAS } & \multirow{2}{*}{$\begin{array}{l}\text { Tipe } \\
\text { Semen }\end{array}$} & \multicolumn{5}{|c|}{ Umur Beton (Hari) } & \multirow{2}{*}{$\begin{array}{c}\text { Jumlah } \\
\text { Benda } \\
\text { Uji }\end{array}$} \\
\hline & & 3 & 7 & 14 & 21 & 28 & \\
\hline \multirow{2}{*}{0.50} & PC I & 3 & 3 & 3 & 3 & 3 & 15 \\
\hline & PCC & 3 & 3 & 3 & 3 & 3 & 15 \\
\hline \multirow{2}{*}{0.55} & PC I & 3 & 3 & 3 & 3 & 3 & 15 \\
\hline & $\overline{\mathrm{PCC}}$ & 3 & 3 & 3 & 3 & 3 & 15 \\
\hline & & & & & \multicolumn{2}{|c|}{ Total Benda Uji } & 60 \\
\hline
\end{tabular}

\subsection{Peralatan Yang Digunakan}

Peralatan yang digunakan dalam penelitian ini sebagian besar telah tersedia di Laboratorium Konstruksi dan Bahan Bangunan Fakultas Teknik Universitas Muhammaddiyah Aceh. Peralatan yang digunakan pada penelitian ini adalah mesin pembebanan tekan (compressive loading machine). Cetakan silinder berdiameter $150 \mathrm{~mm}$ dengan ketinggian $300 \mathrm{~mm}$, timbangan dengan berbagai kapasitas, pengaduk beton (molen) berkapasitas $0,3 \mathrm{~m}^{3}$.

\subsection{Prosedur penelitian}

Prosedur penelitian yang dilakukan meliputi pekerjaan persiapan, pemeriksaan material, pembuatan dan perawatan serta pengujian benda uji. Pekerjaan persiapan meliputi perhitungan teoritis, persiapan cetakan untuk benda uji silinder yaitu cetakan standar yang tersedia dilabotarium (diameter $15 \mathrm{~cm}$ tinggi $30 \mathrm{~cm}$ ). Semua pekerjaan persiapan ini dilakukan dilabotarium Kontruksi dan Bahan Bangnan Fakultas Teknik Universitas Muhammadiyah Aceh.

\subsection{Analisa Bahan}

Sifat-sifat fisis agregat yang akan diperiksa antara lain, berat jenis (Spesific gravity), absorpsi (absorbsion), berat volume (bulk density), analisa saringan (sieve analysis) serta susunan butiran agregat.

\subsubsection{Pengukuran berat jenis dan absorbsi agregat}

Perencanaan campuran beton dalam penelitian ini didasarkan menurut American Concrete Institute (ACI 211.1-91), yang menyatakan bahwa pemilihan komposisi beton perlu memperhatikan keseimbangan antara biaya yang ekonomis dan kebutuhan-kebutuhan 
JURNAL TEKNIK SIPIL

Universitas Muhammadiyah Aceh

Volume 7 Nomor 1 (Juni 2018)

seperti kekuatan (strength), ketahanan (durability), kepadatan (density), kemudahan beton untuk ditempatkan (placeability), dan tampilan (appearance) beton.

\subsubsection{Pengadukan Beton}

Sebelum pekerjaan pengocoran dimulai, masing-masing material ditimbang beratnya sesuai dengan perbandingan campuran yang diperoleh dari rancangan campuran beton ( $\mathrm{mix}$ design). Cetakan benda uji silinder dioles dengan oli yang bertujuan untuk memudahkan pembukaan cetakan setelah beton mengeras. Alat pencampur yang digunakan adalah molen dengan tenaga penggerak dinamo listrik. Sebelum dilakukan pengocoran, wadah dibahasi dengan air terlebih dahulu demikian juga dapat wadah penampungan beton segar. Hal ini bertujuan agar beton tidak melekat pada wadah sehingga beton tidak tertinggal. Pengadukan beton dilakukan dengan memasukkan material pembentuk beton yaitu agregat kasar, pasir kasar, pasir halus, semen dan air secara berturut-turut kedalam molen. Lamanya waktu pengadukan sekitar 2 menit.

\subsubsection{Pembuatan Benda Uji}

Pembuatan benda uji silinder beton dilakukan dengan memasukkan beton kedalam cetakan yang telah disediakan di labotarium. Cetakan ini diisi bertahap dalam tiga lapisan, kemudian dilakukan pemadatan dengan manusukkan tongkat baja sebanyak 25 kali pada setiap lapisanya $\pm 10 \mathrm{~cm}$. Setelah cetakan penuh, sisi cetakan benda uji diketuk dengan palu karet agar lubang bekas tusukan menutup kembali, bagian atas benda uji dibuat capping.

\subsubsection{Perawatan Benda Uji}

Perawatan benda uji dilakukan 1 hari setelah pengocoran dilakukan, benda uji

tersebut dituliskan tanggal pengecoran, FAS dan kode benda uji dengan menggunakan spidol, agar benda uji tersebut tidak tertukar dengan benda uji yang lain. Kemudian benda uji tersebut dimasukkan kedalam bak air yang telah ada di laboratorium Kontruksi dan Bahan Bangunan Fakultas Teknik Universitas Muhammadiyah Aceh, untuk perawatan benda uji tersebut sampai dengan umur 2, 6, 13, 20 dan 27 hari dan dikeluarkan 1 hari sebelum tanggal pengujian untuk dikeringkan dengan cara diangin-anginkan.

\subsubsection{Pengujian kuat tekan beton}

Benda uji silinder dibebani setelah berumur 3, 7, 14, 21, dan 28 hari. Pengujian dilakukan dengan mesin penguji kuat tekan sesuai perencanaan pada Tabel 3.1. Sebelum pengujian, benda uji ditimbang beratnya dan diukur dimensinya. Pembebanan benda uji dilakukan dengan cara memberikan beban tekan aksial secara perlahan-perlahan sampai benda uji mengalami dan tidak terjadi peningkatan beban yang mampu dipikul sesuai dengan SNI 03-1973-1990. 
JURNAL TEKNIK SIPIL

Universitas Muhammadiyah Aceh

Volume 7 Nomor 1 (Juni 2018)

\section{HASIL DAN PEMBAHASAN}

\subsection{Hubungan Umur Beton dan Nilai Kuat Tekan}

Pengujian kuat tekan beton dilakukan pada umur 3, 7, 14, 21, dan 28 hari. Metode pengujian kuat tekan beton dilakukan sesuai dengan uraian pada bab III. Nilai kuat tekan beton terkait variasi FAS dan umur beton untuk masing-masing tipe semen dapat dilihat pada gambar 4.1 berikut.

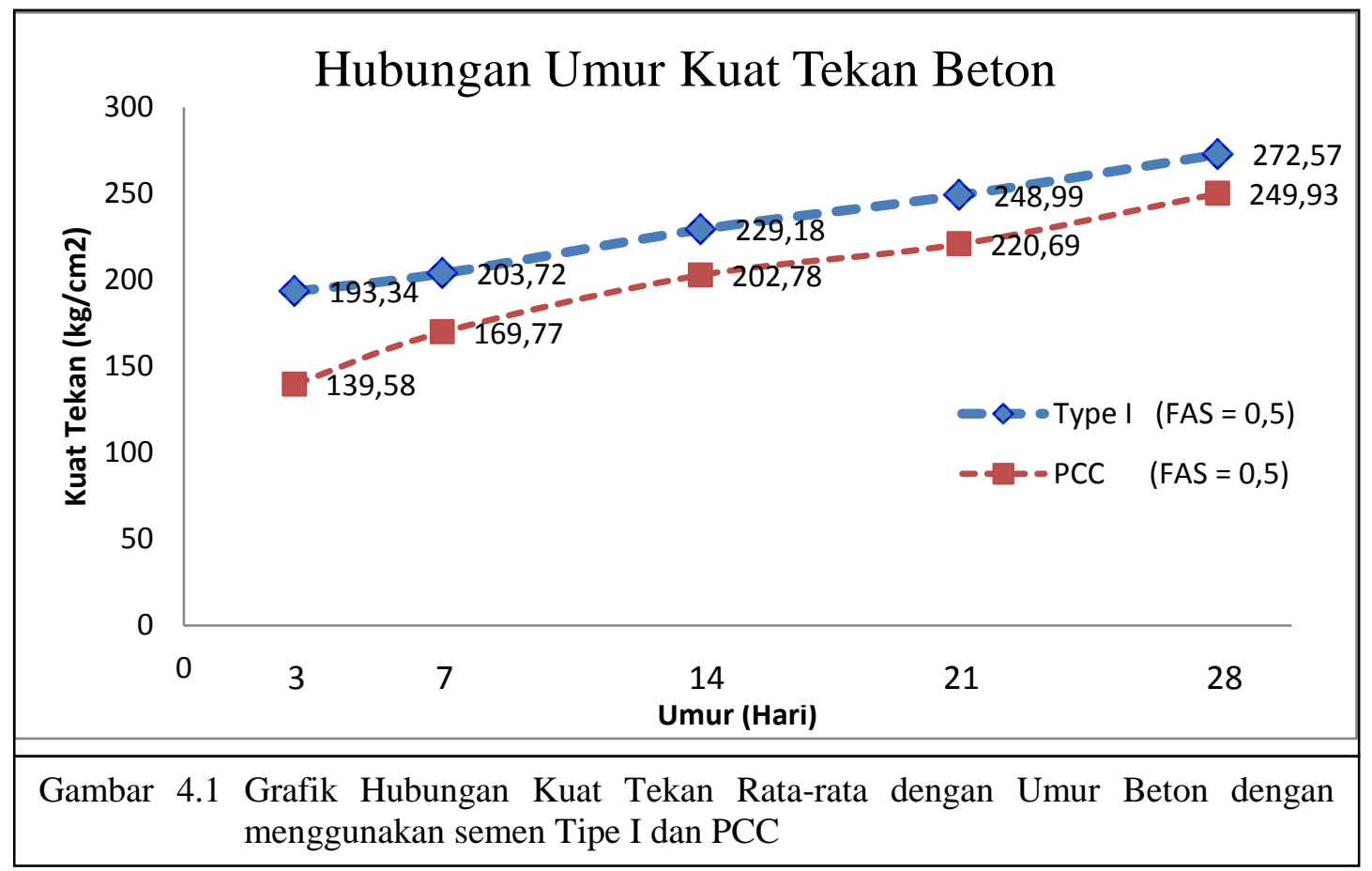

Berdasarkan gambar 4.1 diperoleh hasil pengujian kuat tekan rata-rata beton FAS 0,50 yang menggunakan semen tipe I untuk umur 3, 7, 14, 21 dan 28 hari berturut-turut adalah sebesar $193,34 \mathrm{~kg} / \mathrm{cm}^{2}, 203,72 \mathrm{~kg} / \mathrm{cm}^{2}, 229,18 \mathrm{~kg} / \mathrm{cm}^{2}, 248,99 \mathrm{~kg} / \mathrm{cm}^{2}$ dan 272,57 $\mathrm{kg} / \mathrm{cm}^{2}$. Sedangkan Untuk semen PCC pada umur yang sama kuat tekannya adalah sebesar $139,58 \mathrm{~kg} / \mathrm{cm}^{2}, 169,77 \mathrm{~kg} / \mathrm{cm}^{2}, 202,78 \mathrm{~kg} / \mathrm{cm}^{2}, 220,69 \mathrm{~kg} / \mathrm{cm}^{2}$ dan $249,93 \mathrm{~kg} / \mathrm{cm}^{2}$. Mengacu kepada hasil pengujian tersebut, diperoleh kesimpulan bahwa nilai kuat tekan beton terus mengalami kenaikan sesuai dengan pertambahan umur beton.

Pada kenaikan nilai kuat tekan beton terkait pertambahan umur beton juga terlihat pada benda uji campuran beton dengan FAS 0,55 seperti diperlihatkan pada gambar 4.2. Berdasarkan gambar 4.2 diperoleh hasil pengujian kuat tekan rata-rata beton FAS 0,55 yang menggunakan semen tipe I untuk umur 3, 7, 14, 21 dan 28 hari berturut-turut adalah sebesar $182,97 \mathrm{~kg} / \mathrm{cm}^{2}, 202,78 \mathrm{~kg} / \mathrm{cm}^{2}, 218,81 \mathrm{~kg} / \mathrm{cm}^{2}, 235,79 \mathrm{~kg} / \mathrm{cm}^{2}$ dan $267,85 \mathrm{~kg} / \mathrm{cm}^{2}$. Sedangkan Untuk semen PCC pada umur yang sama kuat tekannya adalah sebesar 149,02 $\mathrm{kg} / \mathrm{cm}^{2}, 169,77 \mathrm{~kg} / \mathrm{cm}^{2}, 177,31 \mathrm{~kg} / \mathrm{cm}^{2}, 209,38 \mathrm{~kg} / \mathrm{cm}^{2}$ dan $243,33 \mathrm{~kg} / \mathrm{cm}^{2}$.

Dengan menjadikan nilai kuat tekan umur 28 hari sebagai acuan nilai kuat tekan beton yang ingin dicapai, maka diperoleh faktor perkembangan kuat tekan beton untuk FAS 
JURNAL TEKNIK SIPIL

Universitas Muhammadiyah Aceh

Volume 7 Nomor 1 (Juni 2018)

0,5 dan 0,55 pada campuran beton yang menggunakan semen tipe I dan PCC.

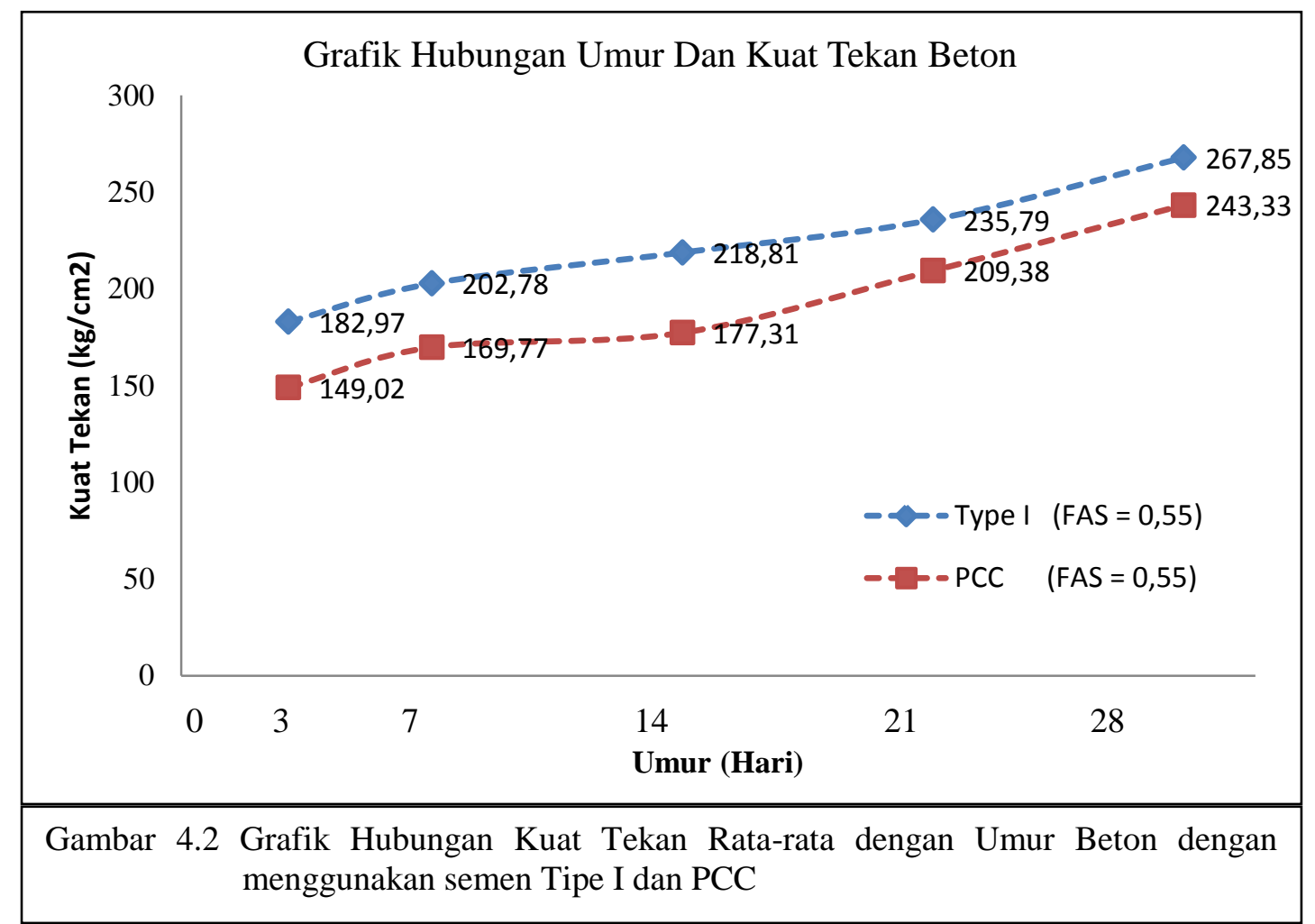

Berdasarkan gambar 4.2 diperoleh hasil pengujian kuat tekan rata-rata beton FAS 0,55 yang menggunakan semen tipe I untuk umur 3, 7, 14, 21 dan 28 hari berturut-turut adalah sebesar $182,97 \mathrm{~kg} / \mathrm{cm}^{2}, 202,78 \mathrm{~kg} / \mathrm{cm}^{2}, 218,81 \mathrm{~kg} / \mathrm{cm}^{2}, 235,79 \mathrm{~kg} / \mathrm{cm}^{2}$ dan 267,85 $\mathrm{kg} / \mathrm{cm}^{2}$. Sedangkan Untuk semen PCC pada umur yang sama kuat tekannya adalah sebesar $149,02 \mathrm{~kg} / \mathrm{cm}^{2}, 169,77 \mathrm{~kg} / \mathrm{cm}^{2}, 177,31 \mathrm{~kg} / \mathrm{cm}^{2}, 209,38 \mathrm{~kg} / \mathrm{cm}^{2}$ dan $243,33 \mathrm{~kg} / \mathrm{cm}^{2}$.

Dengan menjadikan nilai kuat tekan umur 28 hari sebagai acuan nilai kuat tekan beton yang ingin dicapai, maka diperoleh faktor perkembangan kuat tekan beton untuk FAS 0,5 dan 0,55 pada campuran beton yang menggunakan semen tipe I dan PCC.

Hasil uji kuat tekan menunjukkan bahwa semakin bertambah umur beton semakin tinggi kekuatan beton yang dihasilkan. Hal ini jelas berkaitan dengan proses pengerasan yang terjadi di dalam pasta semen sehubungan dengan perbedaan reaktivitas masing-masing mineral pembentuk semen di sisi lain, melambatnya perkembangan kekuatan beton pada umur panjang dapat disebabkan karena proses hidrasi semakin sulit dilaksanakan berkaitan dengan semakin meningkatnya jumlah produk hidrasi dan berkurangnya jumlah air atau akses yang tersedia untuk melangsungkan reaksi. 
JURNAL TEKNIK SIPIL

Universitas Muhammadiyah Aceh

Volume 7 Nomor 1 (Juni 2018)

Tabel 4.1 Perbandingan Kuat Tekan Semen Andalas PCC Terhadap Semen Andalas Tipe I Pada Setiap FAS 0,50 dan 0,55

\begin{tabular}{|l|l|l|l|l|l|l|}
\hline \multirow{2}{*}{ FAS } & \multirow{2}{*}{ Tipe Semen } & \multicolumn{5}{|c|}{ Perbandingan Kuat Tekan Terhadap Semen Tipe I } \\
\cline { 3 - 7 } & & 3 hari & 7 hari & 14 hari & 21 hari & 28 hari \\
\hline \multirow{2}{*}{0,50} & Tipe I & 0,71 & 0,75 & 0,84 & 0,91 & 1,00 \\
\cline { 2 - 7 } & PCC & 0,56 & 0,68 & 0,81 & 0,88 & 1,00 \\
\hline \multirow{2}{*}{0,55} & Tipe I & 0,68 & 0,76 & 0,82 & 0,88 & 1,00 \\
\cline { 2 - 7 } & PCC & 0,61 & 0,70 & 0,73 & 0,86 & 1,00 \\
\hline
\end{tabular}

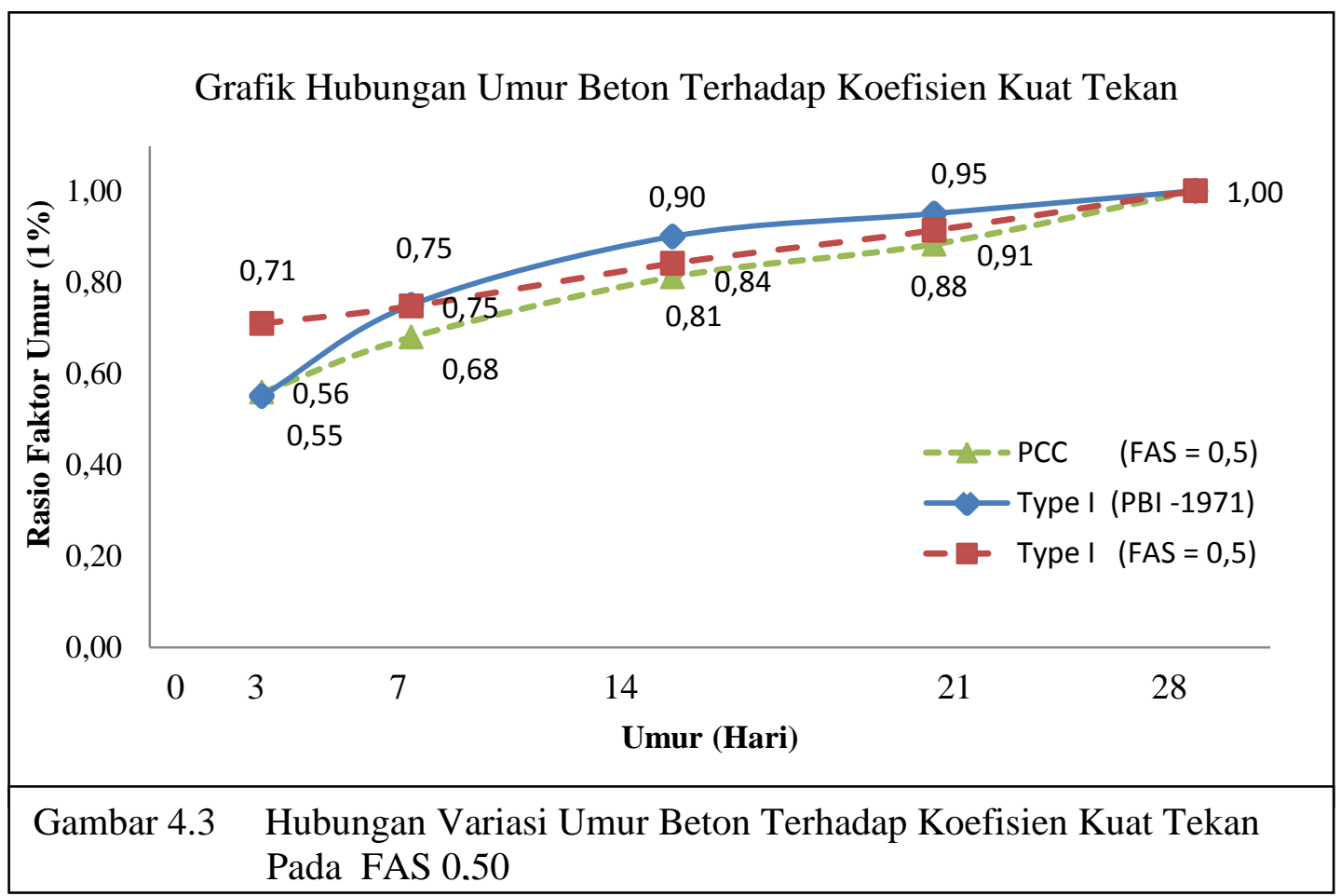

Hasil gambar 4.3 menampilkan hubungan variasi rasio umur beton yang menggunakan semen Tipe I pada umur 3 hari melebihi nilai PBI-1971, sedangkan pada umur $7,14,21$, dan 28 hari, sangat melambat untuk mencapai hubungan variasi umur beton sesuai PBI-1971. 
JURNAL TEKNIK SIPIL

Universitas Muhammadiyah Aceh

Volume 7 Nomor 1 (Juni 2018)

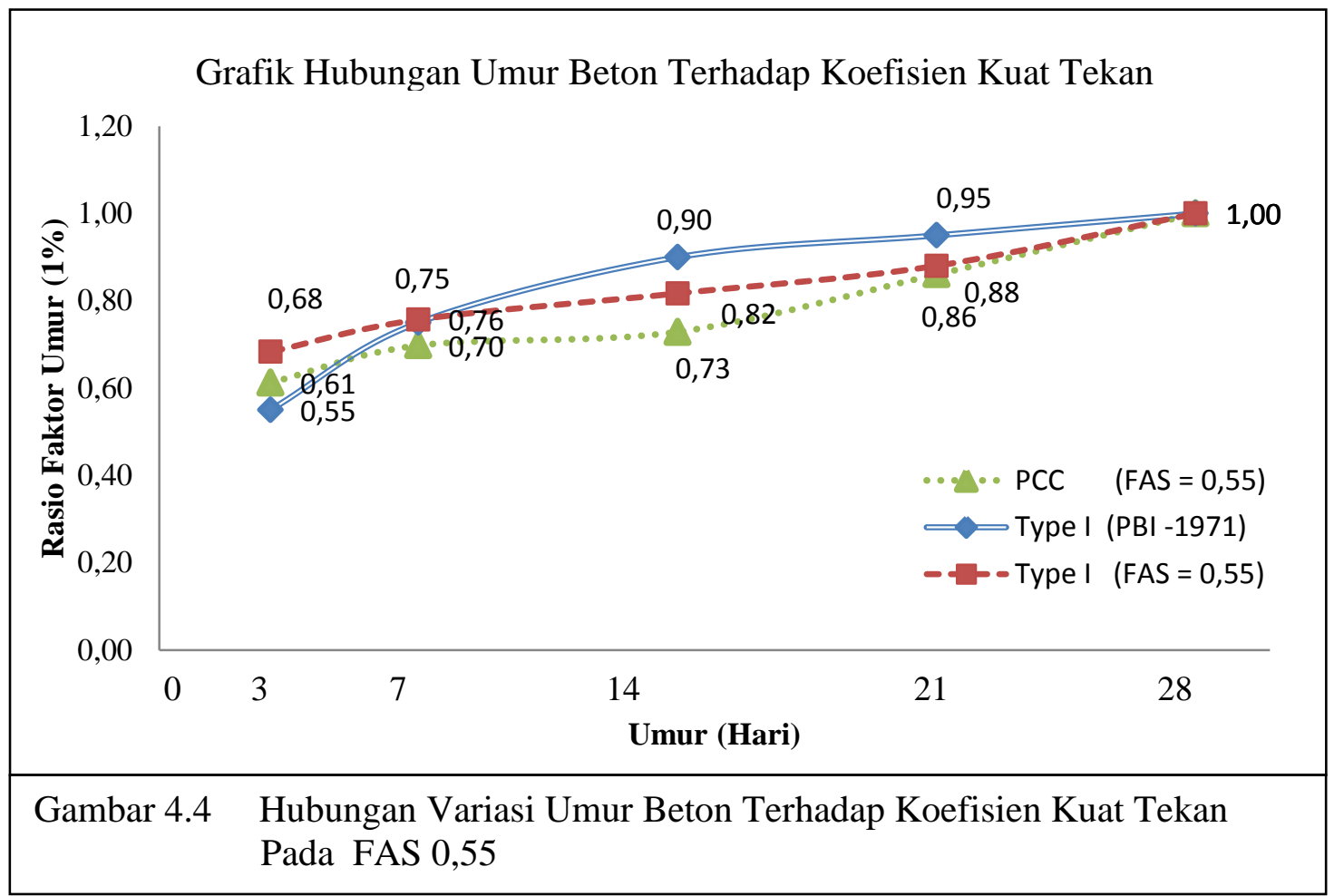

Hasil gambar 4.4 menampilkan hubungan variasi rasio umur beton yang menggunakan semen Tipe I pada umur 3 hari dan 7 hari melebihi nilai PBI-1971, sedangkan pada umur 7, 14, 21, dan 28 hari, sangat melambat untuk mencapai hubungan variasi umur beton pada PBI-1971. Berdasarkan hasil penelitian diperoleh informasi bahwa perkembangan kuat tekan beton pada umur sampai dengan 3 hari lebih tinggi dari pada koefisien yang tercantumkan di PBI-1971.

\section{KESIMPULAN DAN SARAN}

\subsection{Kesimpulan}

Hasil pengujian koefisien kuat tekan untuk umur beton 3 hari lebih tinggi dari koefisien yang dicantumkan pada PBI-1971 baik pada FAS 0,5 dan 0,55 pada campuran beton yang menggunakan semen tipe I dan PCC .

Koefisien nilai kuat tekan umur 7 hari sampai 28 hari lebih rendah dari nilai koefisien yang tercantum pada PBI-1971, selain itu juga diperoleh kesimpulan bahwa nilai koefisien kuat tekan beton PCC lebih rendah dari semen tipe I, baik pada FAS 0,5 ataupun 0,55 .

\subsection{Saran}

Disarankan menggunakan benda uji (sampel) yang lebih banyak untuk setiap umur beton sehingga diperoleh data yang lebih akurat. 
JURNAL TEKNIK SIPIL

Universitas Muhammadiyah Aceh

Volume 7 Nomor 1 (Juni 2018)

Dapat juga ditinjau dengan mengkaitkan benda uji yang diteliti dengan mutu beton rencana (sasaran), selain nilai FAS sehingga pertumbuhan nilai kuat tekan beton terkait umurnya dalam mencapai kuat tekan karakteristiknya dapat diobservasi lebih detail.

\section{DAFTAR KEPUSTAKAAN}

Anonim, 1982, Persyaratan Umum Bangunan Indonesia, Departemen Pekerjaan Umum, Jakarta.

Anonim, 1991, Perencanaan Campuran Beton, Departemen Pekerjaan umum, Bandung.

Anonim, 2004, Annual Book of American Society for Testing and Materials Standard (ASTM Standard), New York, USA.

Anonim, 2005, Standard Practice for Selecting Proportions for Normal Heavyweight, and Mass Concrete (ACI 211.1-91), American Concrete Institute.

Amri, S., 2005, Teknologi Beton A-Z, Universitas Indonesia, Jakarta.

Hanafiah, M. A, 1995, Merencanakan Komposisi Campuran Beton Struktural Laboratorium Konstruksi Dan Bahan Bangunan Fakultas Teknik Universitas Syiah kuala Darussalam- Banda Aceh.

Mulyono, T., 2005, Teknologi Beton, Penerbit ANDI, Yogyakarta.

Murdock, L. J., dan Brooks, K. M., 1999, Bahan dan Praktek Beton, terjemahan Hindarko, S., Penerbit Erlangga, Jakarta.

Sagel, R., 1993. Pedoman Pengerjaan Beton, Seri Beton 2, Erlangga,

Subakti, 1995, Teknologi Beton, Institut Teknologi, Surabaya. 